\title{
Clinicopathological Aspects and Diagnostic Problems in Patients with Intraductal Papillary Neoplasm of the Bile Duct
}

\author{
ATSUSHI NANASHIMA ${ }^{1}$, NAOYA IMAMURA ${ }^{1}$, YORIHISA SUMIDA ${ }^{2}$, \\ MASAHIDE HIYOSHI ${ }^{1}$, TAKEOMI HAMADA ${ }^{1}$ and TAKESHI NAGAYASU ${ }^{2}$ \\ ${ }^{1}$ Division of Hepato-Biliary-Pancreas Surgery, Department of Surgery, \\ University of Miyazaki Faculty of Medicine, Kiyotake, Japan; \\ ${ }^{2}$ Department of Surgical Oncology, Nagasaki University Graduate School of Biomedical Sciences, Sakamoto, Japan
}

\begin{abstract}
Background/Aim: Intraductal papillary neoplasm of the bile duct (IPNB) is defined as a non-invasive malignancy and disparity of its histological diagnosis with related diseases remains. Patients and Methods: Twenty-six cases of IPNB and 12 of papillary adenocarcinomas (PAC) at two Institutes were investigated. Results: The prevalence of biliary dilatation and mucin secretion in the group with $I P N B$ was significantly higher compared to the group with PAC $(p<0.01)$. IPNB was predominantly located in the proximal bile duct compared to the location of PAC $(p<0.01)$. Mis-matching of a second histological diagnosis was observed in $27 \%$ of IPNB and $25 \%$ of PAC, respectively. The prevalence of tumor relapse was significantly higher in $P A C$ than in IPNB $(p<0.05)$, and the overall survival was significantly better in IPNB than in PAC $(p<0.01)$. Conclusion: Although IPNB is currently defined under histological criteria, morphologies were various and disparity in histological diagnosis for IPNB remains problematic when the clinical strategy is contemplated.
\end{abstract}

In the early 2000s, it was Chen et al. (1) and Nakanuma et al. $(2,3)$ who first proposed the concept of a unique biliary tumor named intraductal papillary neoplasm of the bile duct (IPNB), that is characterized by a markedly dilated and cystic biliary system and multifocal papillary epithelial lesions with or without mucin production. In IPNB, solid,

This article is freely accessible online.

Correspondence to: Atsushi Nanashima, MD, Division of Hepatobiliary-pancreas Surgery, Department of Surgery, University of Miyazaki Faculty of Medicine, 5200 Kihara, Kiyotake, Miyazaki 889-1692. Japan. Tel: +81 985852905, Fax: +81 985853780, e-mail: a_nanashima@med.miyazaki-u.ac.jp

Key Words: Intraductal papillary neoplasm of bile duct, papillary adenocarcinoma, resection, pathological diagnosis. irregular, or thickened lesions in the cystic or dilated bile duct are considered evidence of malignancy on macroscopic or image findings (2-5). These intraluminal papillary tumors of extra- or intrahepatic bile ducts usually exhibit precancerous dysplasia or are well-differentiated carcinoma in situ (1-3). IPNB is purported to be associated with the superficial spread of carcinoma cells along the biliary mucosa without invasiveness $(6,7)$. The papillary type or intraductal growth type cholangiocarcinoma with or without mucin production also exhibits unique characteristics including better prognosis after surgery (7-9). Although a similarity between IPNB and this type of cholangiocarcinoma was observed, the histological structures may not always be the same. IPNB is a counterpart of intraductal papillary mucin-producing neoplasm (IPMN) of the pancreas (10-12). Recent pathological studies showed that mucin-producing intrahepatic cholangiocarcinoma (ICC) or extrahepatic bile duct carcinoma, oncocytic biliary cystadenoma, cystoadenoma/cystadenocarcinoma with luminal communication with the bile duct, in addition to biliary papilloma/papillomatosis, could be included as IPNB (9-10). That is, IPNB is proposed to include collectively these biliary tumors that have so far been diagnosed under different terms. IPNB is considered to be of relatively lowgrade malignancy $(1-3,6-9,13,14)$. Since the concept of IPNB was proposed, the pathogenesis and clinical features have been clarified, which were reviewed by Japanese physicians and pathologists (15).

This category has been classified within the category of a specific type of biliary neoplasm by the World Health Organization (WHO) classification 2010 (16), and IPNB is well known worldwide at this time. Furthermore, three types of pre-invasive lesion of bile duct tumor were also indicated in the sixth edition of the General Rules for Clinical and Pathological Studies on Cancer of the Biliary Tract in 2013 as follows: i) biliary intraepithelial neoplasm, ii) IPNB or intracystic papillary neoplasm, and iii) mucinous cystic neoplasm (17). IPNB-originating advanced 
A

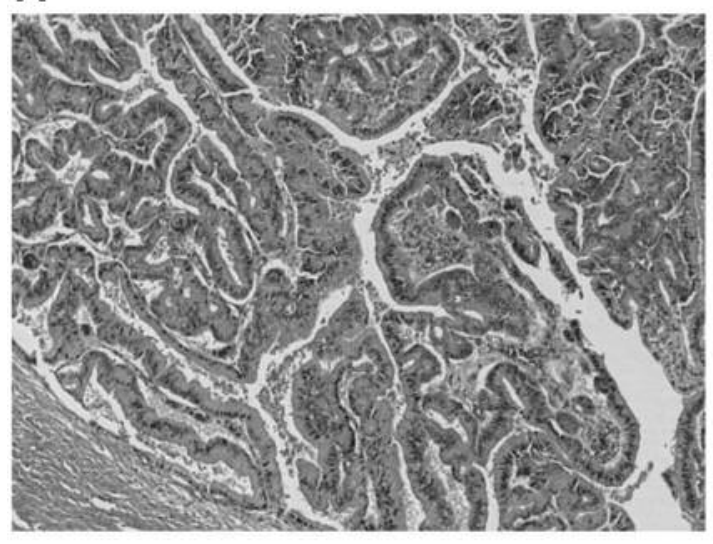

B

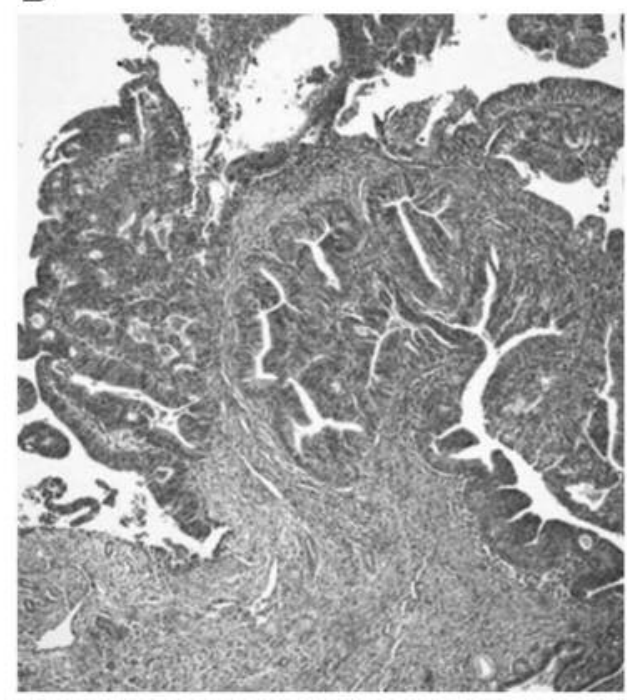

Figure 1. Representative images of histology diagnosed as intraductal papillary neoplasm of the bile duct (IPNB) (A) and papillary adenocarcinoma $(P A C)(B)$. Diagnostically, IPNB is defined as a neoplasm of the bile duct showing uniformly cuboidal to columnar, papillary, well-differentiated and fibrovascular cores. Other neoplasms without these characteristics were defined as PAC.

bile duct carcinoma has also been reported $(18,19)$. However, the definitive similarity and differentiation between IPNB and associated biliary neoplasms may still be unclear in some cases.

We retrospectively examined 26 cases diagnosed as IPNB and 12 cases of non-IPNB papillary neoplasms of the bile duct at two institutes and clarified the clinicopathological manifestations of IPNB and similar papillary adenocarcinoma (PAC). Furthermore, issue regarding histological diagnosis is discussed on the basis of our experience.

\section{Patients and Methods}

Patients. Our study group comprised 42 consecutive patients (26 men, 16 women) who underwent surgical resection at two institutes: the Department of Surgical Oncology, Nagasaki University Graduate School of Biomedical Sciences, Japan [between January 1994 and March $2015(n=14)]$ and in the Division of Hepato-BiliaryPancreatic Surgery (the former Department of Surgical Oncology and Regulation of Organ Function until March 2015), Department of Surgery, University of Miyazaki Faculty of Medicine, Japan [between January 2000 and May $2017(n=28)$ ]. In these series, the total number of bile duct carcinomas and ICC were 107 and 88, respectively, at Nagasaki University, and 130 and 44, respectively, at the University of Miyazaki. These included intra- or extra-hepatic IPNB in 16 patients and PAC in 12 patients, all of which were eventually diagnosed by expert pathologists. Pathological diagnosis with immunohistochemistry and consultation were performed by the expert pathologists in the field of biliary diseases.

Pathological definition. All tumors were macroscopically characterized by a papillary epithelial lesion or a markedly dilated and cystic biliary lesion with or without mucin production, which were located at the intra- or extrahepatic bile ducts. Mucinous cystic neoplasm with ovarian-like stroma or papillary neoplasm of the gall bladder were excluded in the present series. Twelve specimens in the Nagasaki series were histologically diagnosed at the institute first, and, in the next step as a confirmation, the Department of Human Pathology Kanazawa University Graduate School of Medicine, which was an advocate with respect to IPNB was consulted regarding pathology. Thereafter, these were confirmed by the nation-wide survey of the Japan Biliary Association. Twenty-six specimens in the Miyazaki series were histologically diagnosed at the institute first, and then were also histologically confirmed by the same nation-wide survey of the Japan Biliary Association. Thus, all 38 specimens were histologically diagnosed, whether IPNB or PAC, and the final diagnosis depended on aspects reviewed by expert pathologists at the second consultation.

Diagnostically, IPNB is defined as a neoplasm of the bile duct showing uniformly cuboidal to columnar, papillary, welldifferentiated and fibrovascular cores. Other neoplasms without these characteristics were defined as PAC. Representative images of each are shown in Figure 1.

All tumors were resected without macroscopic exposure of the amputated section. We referred to the sixth edition of The General Rules for the Clinical and Pathological Study of Primary Liver Cancer by the Liver Cancer Study Group of Japan (20) and the sixth edition of General Rules for Clinical and Pathological Studies on Cancer of the Biliary Tract by the Japanese Society of HepatoBiliary-Pancreatic Surgery (17) to evaluate the clinicopathological findings in malignancies.

Other measures and statistical analysis. Tumors were preoperatively assessed by computed tomography, magnetic resonance cholangiography, and cholangiography. Surgical resections were performed en bloc based on the preoperative imaging diagnosis, and lymph 
Table I. Comparison of the preoperative demographics, laboratory data and image findings between groups with intraductal papillary neoplasm of the bile duct (IPNB) and papillary adenocarcinoma (PAC).

\begin{tabular}{|c|c|c|c|}
\hline Characteristic & IPNB $(n=26)$ & $\mathrm{PAC}(\mathrm{n}=12)$ & $p$-Value \\
\hline Gender: Male/female, $\mathrm{n}=24(63 \%) / 14(37 \%)$ & $16 / 10$ & $8 / 4$ & $>0.99$ \\
\hline Mean age $\pm \mathrm{SD}$ (range), years & $68 \pm 11(45-81)$ & $69 \pm 7(53-78)$ & 0.85 \\
\hline \multicolumn{4}{|l|}{ Symptoms, $\mathrm{n}=38(100 \%)$} \\
\hline Asymptomatic with abnormal LFT & 12 & 3 & \multirow[t]{4}{*}{0.16} \\
\hline Abdominal fever or pain & 10 & 3 & \\
\hline Jaundice & 1 & 2 & \\
\hline Other & 3 & 4 & \\
\hline \multicolumn{4}{|l|}{ History of disease, $n=35(92 \%)$} \\
\hline Biliary & $10(38 \%)$ & $1(8 \%)$ & 0.25 \\
\hline Hypertension & $5(19 \%)$ & $5(42 \%)$ & 0.29 \\
\hline Chronic liver & $4(\mathrm{HBV}$ in 3$)$ & 0 & 0.16 \\
\hline Diabetes & $5(19 \%)$ & $5(42 \%)$ & 0.29 \\
\hline Co-existence of multiple cancer & 5 (triple in one) $(32 \%)$ & 0 & 0.16 \\
\hline \multicolumn{4}{|l|}{ Preoperative findings } \\
\hline Long-term follow-up $>6$ months, $n=8(21 \%)$ & $6(23 \%)$ & $2(17 \%)$ & \multirow[t]{2}{*}{0.98} \\
\hline Follow-up range, months & $(6-84)$ & $(9-20)$ & \\
\hline \multicolumn{4}{|l|}{ Increased tumor markers, $\mathrm{n}=22(58 \%) *$} \\
\hline CEA $(>5 \mathrm{ng} / \mathrm{ml})$ & $7(28 \%)$ & $5(46 \%)$ & 0.52 \\
\hline CA19-9 (>37 U/ml) & $6(24 \%)$ & $4(33 \%)$ & 0.84 \\
\hline \multicolumn{4}{|l|}{ Image findings } \\
\hline \multicolumn{4}{|l|}{ Biliary dilatation , $\mathrm{n}=20(53 \%)$} \\
\hline Without biliary stricture & 15 & 3 & \multirow[t]{3}{*}{0.0031} \\
\hline With biliary stricture & 5 & 9 & \\
\hline Cystic, $n=6(16 \%)$ & 6 & 0 & \\
\hline Mucus secretion, $\mathrm{n}=16(42 \%)$ & $16(62 \%)$ & 0 & 0.0013 \\
\hline Preoperative biliary drainage, $\mathrm{n}=18(47 \%)$ & $9(35 \%)$ & $9(75 \%)$ & 0.049 \\
\hline \multicolumn{4}{|l|}{ Endoscopic biopsy or cytology: } \\
\hline Not-malignant/malignant, $\mathrm{n}=3(8 \%) / 14(37 \%)$ & $2 / 6$ & $1 / 8$ & 0.562 \\
\hline \multicolumn{4}{|l|}{ Tumor location } \\
\hline Intra-hepatic, $\mathrm{n}=15(39 \%)$ & 15 & 0 & \multirow[t]{2}{*}{0.0079} \\
\hline Extra-hepatic (proximal/distal) $n=23(61 \%)$ & $11(8 / 4)$ & $12(4 / 8)$ & \\
\hline Maljunction of PBD, $n=0(0 \%)$ & 0 & 0 & ND \\
\hline
\end{tabular}

LFT: Liver function test, CA19-9: carbohydrate antigen 19-9, CEA: carcinoembryonic antigen, HBV: hepatitis B virus, ND: not determined. *Beyond the upper limit of normal range.

node dissection was performed on the hepatoduodenal ligament, surrounding the pancreatic head and para-aortic lesions. On the basis of the Declaration of Helsinki 2013, the study design was approved by the Ethics Committee of both Nagasaki University Hospital (\#17041706 on April 18, 2017) and University of Miyazaki Faculty of Medicine (\#O-0118 on February 2, 2017). Informed consent was obtained by the opt-out procedure at each institute for approximately 1 month according to the planning documents of the study.

Continuous data are expressed as means \pm standard deviation (SD). Data were compared between groups using one-way analysis of variance (ANOVA) and were examined with the Mann-Whitney $U$-test. Comparisons of categorical data were performed with the chi-square test. Potentially predictive variables were identified using a significance level of $p<0.05$ by univariate analysis. A two-tailed p-value of less than 0.05 was considered significant. The Statistical Package for the Social Sciences (SPSS) version 18.0 software (SPSS, Chicago, IL, USA) was used for all statistical analyses.

\section{Results}

Patients. The prevalence of IPNB $(n=16)$ and PAC $(n=12)$ in the entire group with ICC and those with extra-hepatic cholangiocarcinoma $(n=237$ and $n=132$, respectively) was $4.3 \%$ and $3.2 \%$, respectively. The prevalence of IPNB and PAC was $15(11.4 \%)$ and 0 , respectively, in patients with ICC, and that of IPNB and PAC was $11(4.6 \%)$ and 12 $(5.1 \%)$, respectively, in those with extra-hepatic cholangiocarcinoma.

Comparison of characteristic. Table I shows the comparison of the preoperative data between the IPNB and PAC groups. Gender, age, prevalence of symptoms at onset, history of previous diseases or comorbidity, family history of biliary neoplasms and the co-existence of 
Table II. Comparison of surgical records and tumor factors between groups with intraductal papillary neoplasm of the bile duct (IPNB) and papillary adenocarcinoma $(P A C)$.

\begin{tabular}{|c|c|c|c|}
\hline Characteristic & IPNB $(n=26)$ & $\operatorname{PAC}(n=12)$ & $p$-Value \\
\hline \multicolumn{4}{|l|}{ Surgical records } \\
\hline \multicolumn{4}{|l|}{ Operation } \\
\hline Hemihepatectomy greater, $\mathrm{n}=25(66 \%)$ & 22 & 3 & \multirow[t]{4}{*}{0.0011} \\
\hline Sectionectomy, $\mathrm{n}=1(3 \%)$ & 1 & 0 & \\
\hline Pancreaticoduodenectomy, $\mathrm{n}=10(26 \%)$ & 3 & 7 & \\
\hline Bile duct resection, $\mathrm{n}=2(5 \%)$ & 0 & 2 & \\
\hline Combined resection of EHBD: Yes, $\mathrm{n}=20(53 \%)$ & 17 & 3 & 0.44 \\
\hline Cancer positive at bile duct stump: Yes & $1(4 \%)^{\mathrm{a}}$ & $1(8 \%)^{b}$ & 1.0 \\
\hline Cancer positive at exposed margin: Yes & $1(4 \%)$ & $2(17 \%)$ & 0.094 \\
\hline Curability: R0/1/2 & $24(92 \%) / 2 / 0$ & $10(83 \%) / 1 / 1$ & 0.40 \\
\hline \multicolumn{4}{|l|}{ Tumor-related factors } \\
\hline \multicolumn{4}{|l|}{ Macroscopic findings } \\
\hline Papillary (expanding/infiltrating) & $24(92 \%)(23 / 1)$ & $12(100 \%)(7 / 5)$ & \multirow[t]{2}{*}{0.88} \\
\hline Other, $\mathrm{n}=2(5 \%)$ & 2 & 0 & \\
\hline Mean size $\pm \mathrm{SD}$ (range), $\mathrm{mm}$ & $28 \pm 13(15-58)$ & $25 \pm 7(53-75)$ & 0.64 \\
\hline \multicolumn{4}{|l|}{ Microscopic diagnosis } \\
\hline Carcinoma in adenoma, $\mathrm{n}=3(8 \%)$ & 3 & 0 & 0.472 \\
\hline Adenocarcinoma (papillary/tubular/other) ${ }^{\mathrm{c}}$ & $23(18 / 4 / 1)$ & $12(7 / 4 / 2)$ & $(0.274)$ \\
\hline \multicolumn{4}{|l|}{ Vessel infiltration: Yes, $n=13$ (34\%) } \\
\hline Lymphatic & $3(12 \%) / 23$ & $6(50 \%) / 6$ & 0.0095 \\
\hline Venous & $2(8 \%) / 24$ & $6(50 \%) / 6$ & 0.0029 \\
\hline Perineural & $3(12 \%) / 23$ & $6(50 \%) / 6$ & 0.0095 \\
\hline \multicolumn{4}{|l|}{ Depth of invasion } \\
\hline \multicolumn{4}{|l|}{ Mucosa/fibromuscular/subserosa or more, } \\
\hline Hepatic infiltration: Yes, $n=5(13 \%)^{\mathrm{d}}$ & $3(13 \%) / 20(87 \%)$ & $2(66 \%) / 1(33 \%)$ & 0.027 \\
\hline Pancreatic infiltration: Yes, $n=3(8 \%)^{\mathrm{e}}$ & $0 / 3(100 \%)$ & $3(43 \%) / 4(57 \%)$ & 0.228 \\
\hline Portal vein or arterial infiltration, $\mathrm{n}=0(0 \%)$ & 0 & 0 & ND \\
\hline Node metastasis: Yes, $\mathrm{n}=5$ (13\%) & $2(8 \%) / 24(92 \%)$ & $3(25 \%) / 9(75 \%)$ & 0.301 \\
\hline Superficial extension $>2 \mathrm{~cm}$ : Yes, $\mathrm{n}=13(34 \%)$ & $11(42 \%) / 15(58 \%)$ & $2(16 \%) / 10(84 \%)$ & 0.158 \\
\hline \multicolumn{4}{|l|}{ Stage, I/II/III, $\mathrm{n}=17(45 \%) / 15(39 \%) / 6(16 \%)$} \\
\hline ICC (I/II/III) & $7 / 4 / 4$ & 0 & ND \\
\hline Proximal origin (I/II/IIIA/IIIb) & $3 / 4 / 0 / 1$ & $2 / 1 / 1 / 0$ & 0.392 \\
\hline Distal origin (IA/IB/IIA/IIB) & $2 / 0 / 0 / 1$ & $1 / 2 / 2 / 3$ & 0.277 \\
\hline \multicolumn{4}{|l|}{ Positive IHC stain, $n=37(97 \%)^{\mathrm{f}}$} \\
\hline MUC1 & $9(53 \%)$ & ND & ND \\
\hline MUC2 & $4(24 \%)$ & & \\
\hline MUC5A & $12(71 \%)$ & & \\
\hline MUC6 & $6(35 \%)$ & & \\
\hline $\mathrm{p} 53$ & $6(35 \%)$ & & \\
\hline Difference of histological diagnosis: Yes/no, $\mathrm{n}(\%)^{\#}$ & $7(27 \%) / 19(73 \%)$ & $3(25 \%) / 9(75 \%)$ & 0.90 \\
\hline
\end{tabular}

EHBD: Extrahepatic bile duct, ICC: intrahepatic cholangiocarcinoma, IHC: immunohistochemistry, Muc: mucin, ND: not determined. aCarcinoma

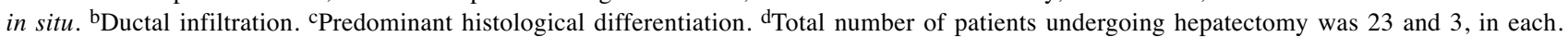
${ }^{\text {e}}$ Total number of patients undergoing pancreatectomy was 3 and 7 , in each. fPerformed in 17 patients with IPNB only. "Difference in final diagnosis between the first pathologist and the consultation. Tumor stage was according to the General Rules for the Clinical and Pathological Study of Primary Liver Cancer (20) and the General Rule for Clinical and Pathological Studies on Cancer of the Biliary Tract (17).

multiple cancers in the patient demographics were similar between the groups. The prevalence of long-term followup over 6 months before surgery and increased tumor marker levels were not significantly different between groups. In image findings, the prevalence of biliary dilatation without biliary stricture and cystic dilatation at the site of main tumor in the IPNB group was significantly higher than that in the PAC group, whereas the prevalence 
Table III. Comparison of the patient outcomes and prognosis between groups with intraductal papillary neoplasm of the bile duct (IPNB) and papillary adenocarcinoma (PAC).

\begin{tabular}{|c|c|c|c|}
\hline Outcome measure & IPNB $(n=26)$ & $\operatorname{PAC}(n=12)$ & $p$-Value \\
\hline \multicolumn{4}{|l|}{ Postoperative course } \\
\hline Morbidity: Yes, $\mathrm{n}=10(26 \%)^{\mathrm{a}}$ & $6(23 \%) / 20(77 \%)$ & $4(33 \%) / 8(67 \%)$ & 0.694 \\
\hline \multicolumn{4}{|l|}{ Long-term outcomes } \\
\hline Postoperative adjuvant treatment & & & 0.15 \\
\hline No, $n=30(79 \%)$ & $23(89 \%)$ & $7(58 \%)$ & \\
\hline Yes (chemotherapy/PDT), n=8 (21\%) & $3(2 / 1)$ & $5(5 / 0)$ & \\
\hline Tumor relapse, $\mathrm{n}=12(32 \%)$ & & & 0.018 \\
\hline No & $21(81 \%)$ & $5(36 \%)$ & \\
\hline Yes (local/distant) & $5(2 / 3)$ & $7(1 / 6)$ & \\
\hline Tumor relapse-free survival & & & $<0.001$ \\
\hline Mean \pm SD (years) & $12.4 \pm 1.2$ & $4.4 \pm 1.6$ & \\
\hline 3 -Year $(\%)$ & 86 & 40 & \\
\hline Overall survival & & & 0.0046 \\
\hline Mean \pm SD (years) & $12.4 \pm 1.2$ & $6.2 \pm 1.4$ & \\
\hline 5 -Year $(\%)$ & 90 & 65 & \\
\hline
\end{tabular}

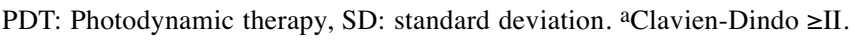

of obstructive biliary dilatation by the main tumor in PAC was significantly higher than that in the IPNB group $(p<0.01)$. Although macroscopic mucin secretion was not observed in patients with PAC, it was observed in $62 \%$ of patients with IPNB patients, which was significantly more frequent $(p<0.01)$. The prevalence of preoperative biliary drainage requirements in patients with PAC was significantly higher than that in the IPNB group $(p<0.05)$. Although the endoscopic biopsy or cytology was accurate in 16 IPNB patients $(62 \%)$ and in 9 patients with PAC $(75 \%)$, the diagnostic rate of malignancy was not significantly different. With respect to the location of primary tumor lesion, all cases of IPNB were predominantly located in the intrahepatic bile ducts, which was not observed in patients with PAC. Extra-hepatic IPNB was predominantly located in the proximal bile duct, particularly perihilar bile duct lesions, which was different from that inpatients with PAC. The prevalence of tumor location was significantly different between groups $(p<0.01)$. Maljunction of pancreato-biliary ducts was not observed in either group.

Due to differences in tumor location and extent, liver resection was predominantly used in patients with IPNB and pancreaticoduodenectomy or bile duct resection in patients with PAC $(p<0.01)$ (Table II). In liver resections, the prevalence of combined resection of the extrahepatic bile duct was not significantly different between the groups. The prevalence of cancer positivity at the bile duct margin and exposed margin was low and also not significantly different between groups. The rate of $\mathrm{R} 0$ resection was not significantly different between groups. One patient (undergoing only extra-hepatic bile duct resection) out of 12 with PAC had R2 resection due to cancer positivity at the bile duct stump.

Macroscopic findings primarily showed papillary or protruding tumor in both groups. Out of 26 patients with IPNB, one showed no solid mass, and another had the nodular-infiltrating type. The tumor size was not significantly different between groups. Histological diagnosis and differentiation were not significantly different between groups. Although each patient had initial histological diagnosis at the first institute and some diagnoses were changed by the second consultation by the expert pathologist, the prevalence of non-matching histological diagnoses was observed in $27 \%$ of patients with IPNB and $25 \%$ of patients with PAC. Prevalence of vessel infiltration was not significantly different between the groups. Distribution of depth of tumor invasion was significantly different between the groups, with mucosal or fibromuscular infiltration being significantly more prevalent in IPNB than in PAC $(p<0.05)$. The prevalence of hepatic or vessel infiltration in patients undergoing hepatectomy was significantly lower in those with IPNB compared with patients with PAC $(p<0.05)$. Prevalence of pancreatic invasion, nodal metastasis, existence of superficial extension over $2 \mathrm{~cm}$, and histological tumor stage were not significantly different between groups. Early stage ICC was predominantly observed in 15 patients with IPNB. The tumor stages of extrahepatic bile duct carcinomas (proximal or distal) did not significantly differ between groups. The prevalence of positivity for mucin antigen by immunohistochemical staining varied in patients with IPNB. 
A

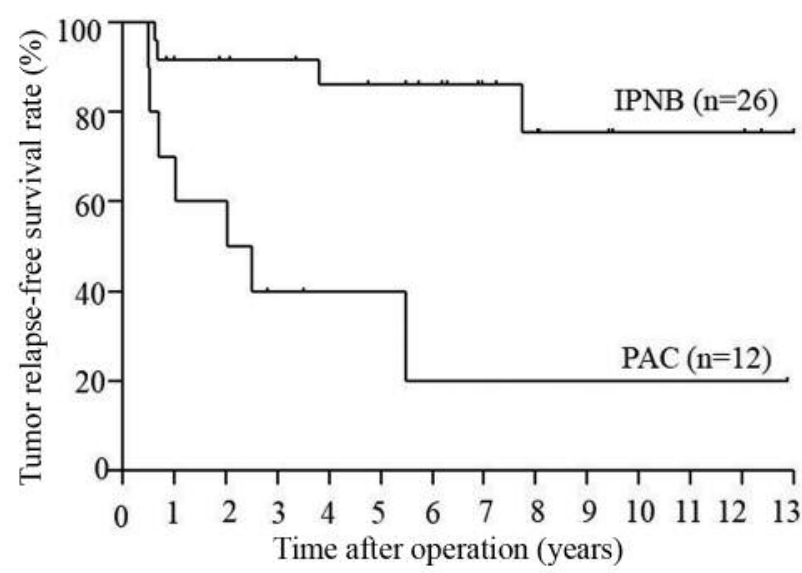

B

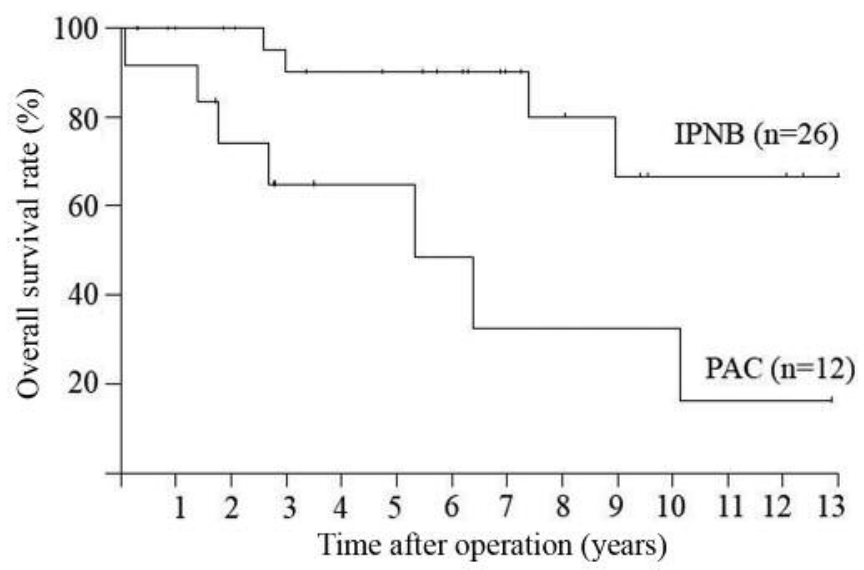

Figure 2. Tumor-free (A) and overall (B) survival in patients with intraductal papillary neoplasm of the bile duct (IPNB) and papillary adenocarcinoma (PAC).

Comparison of outcomes. In Table III, the prevalence of severe postoperative complications did not significantly differ between the groups. One patient with PAC died during the hospital stay due to an operative complication. The prevalence of adjuvant treatment was not significantly different between groups. Tumor relapse was significantly move frequent in PAC than in IPNB $(p<0.05)$. In particular, distant metastases were predominantly observed in PAC. On the basis of this result, the tumor relapse-rate and tumor relapse-free survival period were significantly better in patients with IPNB than in those with PAC $(p<0.05$ and $p<0.01$, respectively) (Table III and Figure $2 \mathrm{a}$ ). The overall survival was also significantly better in those with IPNB than in those with PAC $(p<0.01)$ (Table III and Figure 2b).

\section{Discussion}

The clinicopathological evaluation and definition of IPNB have been developed in Japan since the first proposal of this disease $(1,2,9,15,20)$ and this concept has been accepted worldwide $(16,21,22)$. However, consistency of histological definition has not been observed, and the controversy of diagnosis is still referred to by clinical physicians and pathologists $(11,21,23)$ Therefore, the clinical aspect of preoperative histological diagnosis and surgical indication has not yet been fully clarified. Our previous reports identified the various tumor morphologies of IPNB, good prognosis, and difficulty in comparison with similar biliary tumors $(19,24-$ 26). The significance of protruding bile duct carcinoma accompanied by widely superficial extension was also reported as characteristics in common with IPNB (27). However, PAC also has characteristics similar to IPNB (28).
In the present study, we compared clinicopathological features, matching of histological diagnoses, and patient prognosis between IPNB and PAC by collecting data at two academic institutes at which the first Author was on staff to clarify the pathophysiology of both neoplasms and problematic issues regarding the definition of histological diagnosis.

Histological definition of discrimination between IPNB and PAC remains difficult, and might be dependent on experienced pathologists. We herein showed representative histological examples of each, however, differential diagnosis was generally controversial between pathologists. In the present study, the final histological decision was entrusted to the second consultation.

The carcinogenesis of biliary neoplasms, including IPNB and PAC, is influenced by chronic biliary inflammatory diseases such as hepatolithiasis, pancreatico-biliary maljunction, and chronic hepatitis $(1,2,11,15,29,30)$ In the latest edition of the General Rule for Clinical and Pathological Studies on Cancer of the Biliary Tract by the Japanese Society of Hepato-Biliary-Pancreatic Surgery (17), the three types of pre-cancerous or less-invasive biliary lesions were as described above. However, at this stage, it might be unusually difficult to determine the cancer origin or etiology by observing invasive bile duct carcinomas. In the present study, these factors were not associated with the difference of occurrence between IPNB and PAC. In the IPNB group, asymptomatic patients with mild liver dysfunction tended to be predominant because biliary obstruction is rare at this stage. To find IPNB or early-stage biliary carcinomas, it is important to find by imaging examination those patients who have chronic hepato-biliary dysfunction, and we also previously emphasized the 
importance of an increased level of alkaline phosphatase (24, 31). One woman with IPNB had worked in the printing industry for many years, and she had metachronous triple cancer. Although the co-existence of multiple cancer was more in keeping with a diagnosis of IPNB, the association with this phenomenon could not be explained. Our previous study of 234 cases of biliary cancer in 597 patients with hepato-biliary-pancreas cancer did not show a significant relation between the occurrence of multiple cancer and any usual parameters of co-diseases, environmental status, and lifestyle habits (32).

In some patients, tumor growth or biliary dilatation were slow and there was a long period before the decision to operate was taken. Two of the patients with IPNB did not show any solid mass lesion detected by conventional imaging examination. The follow-up strategy was clearly defined in IPMN of the pancreas, which is considered the counterpart disease of IPNB $(10,20,23)$. If the clinical or imaging characteristics indicating low-grade malignancy in some patients with IPNB were clarified, a similar strategy to IPMN would be used. Accurate histological diagnostic discrimination between IPNB and PAC obtained by biopsy specimen seemed to be difficult at this stage; it is also difficult to follow-up for a long period, except in the case of a homogenously low-grade adenomatous lesion. As shown in the present study, accuracy of diagnosis of malignancy by preoperative endoscopic-assisted biopsy or cytology was not satisfied even in voluminous tumors, and preoperative diagnosis of IPNB was not obtained at all. Morphological imaging characteristics such as diffuse biliary dilatation without stricture or cystic formation, and mucin production, demonstrated the higher possibility of the lesion being an IPNB and, therefore, the decision on the degree of resection would considered these findings or results of endoscopic cholangiographic examination $(7,33)$. Although an increased level of carbohydrate antigen 19-9 (CA19-9) is a useful auxiliary parameter in biliary malignancies including IPNB (34), the prevalence of increase was not high and the mildly increased level in our series was limiting. Eventually, we decided the operative indication and extent based on imaging examination in all cases and on biopsy results in some cases in both IPNB and PAC groups. As the tumor occurred at the large bile duct in both IPNB and PAC, hemihepatectomy or more extended hepatectomy was necessary when liver resection was also necessary, as was found in a previous report (7). Therefore, well-preserved liver function was necessary. The relatively high rate of R0 curability was maintained and, therefore, curative surgery would be possible in most cases of both IPNB and PAC.

Both IPNB and PAC exhibited morphology of papillary growth, and one case of IPNB had specific characteristics, which we previously reported as a case report (24), in which no mass components were found, but only diffuse dilatation of the bile duct in evenly resected specimens. In this case, histological examination showed that the low papillary structure of adenoma was dominant and glandular cells of carcinoma in situ were partially observed. This lesion spread superficially along the epithelium of the extrahepatic bile duct, having a normal appearance without dilatation. Thus, IPNB may rarely exhibits peculiar development and demonstrated a wide spectrum of features histologically (35). Histologically, the adenoma component was only observed in IPNB, not in PAC, in the present series. This raises the question of whether the precancerous origin is different between IPNB and PAC, or whether the timing of onset was simply different. As the previous reports showed that IPNB potentially had lower malignancy or invasiveness $(7,9,15,18,22,28,35)$, less-invasive findings such as vessel infiltrations, depth of invasion, surrounding stromal invasion, and nodal metastasis in IPNB were significant in comparison with PAC in the present study. Regarding superficial extension of the main tumor, this characteristic was significantly more frequent in the papillary-type cholangiocarcinoma compared to the nodular or flat-type carcinomas in the previous reports and in our report $(7,27$, 36). Okamoto et al. examined the characteristics of papillary carcinomas, finding superficial extension in 53\%, multicentric carcinogenesis, pancreatco-biliary maljunction, and a survival benefit for clearance by surgical resection (36). In the present series, the existence of superficial extension was not significantly characterized in each group. In distal bile duct carcinomas, advanced stage tended to be observed more in PAC, but not significantly due to the limited number of patients. Pathologically, IPNB purportedly is less malignant in comparison with PAC. However, the problem of histological diagnosis was found, and conversion of the initial pathologist's diagnosis by the consultation pathology was observed in $27 \%$ of cases of IPNB and $25 \%$ of PAC in the present study. The series of Nagasaki University was consulted by the honorable Professor Nakanuma (University of Kanazawa), who was one of the proponents of IPNB, accompanied by the institution pathologists in all cases. The series of University of Miyazaki was consulted at the time of the nationwide histological surveillance by the Japanese Society of HepatoBiliary-Pancreatic Surgery, and some cases were converted between groups. Eventually, all specimens were checked by expert pathologists; however, we asked what defining characteristics the experienced pathologists used. The bias of histological diagnosis with respect to IPNB would be considered if the cases accompanied by low-grade malignancy tended to be defined as IPNB. Although the pathologist's opinion might be controversial for the definition of IPNB, Zen recently described three possible different concepts with respect to IPNB as follows: i) IPNB 
was diagnosed in cases in which the characteristic histological lesion was partially confirmed (wide sense); ii) denying the concept of IPNB, all lesions were diagnosed as papillary cholangiocarcinoma; and iii) IPNB was strictly diagnosed based on homogenously represented histological characteristics (narrow sense) (37). According to each concept, the prevalence of IPNB would be changed and the understanding of pathogenesis would also be changed. We suppose that our series might be classified by wide-sense examinations. The immunohistochemical stain of mucin protein expression was usually applied in order to diagnose IPNB (7); however, the pattern of mucin expression varied in IPNB due to difference in microscopic subtypes, and some showed negative expression. It might be unclear whether mucin expression is appropriate for defining clinical characteristics of IPNB. Molecular examination in IPNB was proposed (38), and this would provide a proper definition or classification. Furthermore, it could be applied to deciding surgical indication using small biopsy specimens in a future step.

In the present series, most patients safely underwent surgical resections, and their prognosis was well followedup. Chemotherapy was primarily used in those with advanced-stage lesions, and photodynamic therapy was applied for cancer-positive hepatic bile duct stump in one case (31); Iocal recurrence was controlled in the latter. From our results for the tumor relapse rate, relapse-free rate, and overall survival rate, patients with IPNB had better prognoses than those with PAC, although the prognosis of PAC was still better in comparison with the predominant type of cholangiocarcinoma, such as nodular- or flat-type extrahepatic bile duct cancer, and mass-forming or periductal invasive type of ICC (39). In IPNB and PAC, it was possible to achieve curative surgery using conventional surgical procedures. Therefore, whether the patient was diagnosed with IPNB or PAC, adjuvant chemotherapy or other adjuvant treatments were given in cases of advancedstage disease such as those with node positive disease or non-curative operations. Understanding the pathogenesis of IPNB and clarifying its malignant potential will allow prolonged preoperative follow-up or reduction of surgery to procedures such as limited bile duct resection or reduce the extent of lymph-node dissection (40). However, we found patients with IPNB and PAC to have tumors with various malignant behaviors; therefore, it was difficult to recommend a surgical strategy, unlike if IPNB could be diagnosed preoperatively at this stage.

As described previously, the histological definition or classification in both IPNB and PAC might still be controversial and differences in institutional or pathologist's approaches may influence the future clinical aspect in IPNB. We previously reported cases resembling biliary diseases, which were metachronous epithelial metastasis of colon cancer (25) and multi-cystic biliary hamartoma (benign) (26). The first case was histologically diagnosed as IPNB, and the consultation pathology evaluated the disease by immunohistochemical examination. The latter case was suspected to be IPNB by the radiologist, and the initial pathologist diagnosed it as a benign cystic tumor. Eventually, the consultation pathologist clarified the rare biliary disease. We stress the need for pathology consultation in cases of suspicious or heterogeneous components of papillary or cystic malignancies in order to avoid bias of histological diagnosis. Furthermore, sharing information or findings in cases of characterized biliary diseases is important in a conference meeting between physicians, radiologists, surgeons, and pathologists.

In conclusion, we have provided a retrospective cohort study of IPNB and compared findings for these patients to those from PAC resembling IPNB. The clinicopathological characteristics of IPNB as having a low malignant potential in comparison to those of PAC were entirely clarified. Adequate timing of surgical treatment provides good outcomes in both IPNB and PAC. A clearer definition of IPNB by a nationwide surveillance or study is required to advance the clinical strategy for therapy of IPNB.

\section{Conflicts of Interest}

Conflicts of interest did not exist for any Author. No financial support was requested or received for this study.

\section{References}

1 Chen TC, Nakanuma Y, Zen Y, Chen MF, Jan YY, Yeh TS, Chiu CT, Kuo TT, Kamiya J, Oda K, Hamaguchi M, Ohno Y, Hsieh LL and Nimura Y: Intraductal papillary neoplasia of the liver associated with hepatolithiasis. Hepatology 34: 651-658, 2001.

2 Nakanuma Y, Sasaki M, Ishikawa A, Tsui W, Chen TC and Huang SF: Biliary papillary neoplasm of the liver. Histol Histopathol 17: 851-861, 2002.

3 Sudo Y, Harada K, Tsuneyama K, Katayanagi K, Zen Y and Nakanuma Y: Oncocytic biliary cystadenocarcinoma is a form of intraductal oncocytic papillary neoplasm of the liver. Mod Pathol 14: 1304-1309, 2001.

4 Yoon KH, Ha HK, Kim CG, Roh BS, Yun KJ, Chae KM, Lim $\mathrm{JH}$ and Auh YH: Malignant papillary neoplasms of the intrahepatic bile ducts: CT and histopathologic features. Am J Roentgenol 175: 1135-1139, 2002.

5 Lim JH, Yi CA, Lim HK, Lee WJ, Lee SJ and Kim SH: Radiological spectrum of intraductal papillary tumors of the bile ducts. Korean J Radiol 3: 57-63, 2002.

6 Kim H, Lim JH, Jang KT, Kim MJ, Lee J, Lee JY, Choi D, Lim HK, Choi DW, Lee JK and Baron R: Morphology of intraductal papillary neoplasm of the bile ducts: radiologic-pathologic correlation. Abdom Imaging 36: 438-446, 2011.

7 Ohtsuka M, Shimizu H, Kato A, Yoshitomi H, Furukawa K, Tsuyuguchi T, Sakai Y, Yokosuka O and Miyazaki M: Intraductal papillary neoplasms of the bile duct. Int J Hepatol 2014: 459091, 2014. 
8 Natov NS, Horton LC and Hegde SR: Successful endoscopic treatment of an intraductal papillary neoplasm of the bile duct. World J Gastrointest Endosc 9: 238-242, 2017.

9 Kubota K, Nakanuma Y, Kondo F, Hachiya H, Miyazaki M, Nagino M, Yamamoto M, Isayama $H$, Tabata M, Kinoshita $H$, Kamisawa $\mathrm{T}$ and Inui $\mathrm{K}$ : Clinicopathological features and prognosis of mucin-producing bile duct tumor and mucinous cystic tumor of the liver: a multi-institutional study by the Japan Biliary Association. J Hepatobiliary Pancreat Sci 21: 176-185, 2014.

10 Zen Y, Fujii T, Itatsu K, Nakamura K, Minato H, Kasashima S, Kurumaya H, Katayanagi K, Kawashima A, Masuda S, Niwa H, Mitsui T, Asada Y, Miura S, Ohta T and Nakanuma Y: Biliary papillary tumors share pathological features with intraductal papillary mucinous neoplasm of the pancreas. Hepatology 44: 1333-1343, 2006.

11 Ohtsuka M, Kimura F, Shimizu H, Yoshidome H, Kato A, Yoshitomi H, Furukawa K, Takeuchi D, Takayashiki T, Suda K, Takano S, Kondo $\mathrm{Y}$ and Miyazaki M: Similarities and differences between intraductal papillary tumors of the bile duct with and without macroscopically visible mucin secretion. Am J Surg Pathol 35: 512-521, 2011.

12 Valente R, Capurso G, Pierantognetti P, Iannicelli E, Piciucchi M, Romiti A, Mercantini P, Larghi A, Federici GF, Barucca V, Osti MF, Di Giulio E, Ziparo V and Delle Fave G: Simultaneous intraductal papillary neoplasms of the bile duct and pancreas treated with chemoradiotherapy. World J Gastrointest Oncol 4: 22-25, 2012.

13 Wan XS, Xu YY, Qian JY, Yang XB, Wang AQ, He L, Zhao HT and Sang XT: Intraductal papillary neoplasm of the bile duct. World J Gastroenterol 19: 8595-8604, 2013.

14 Devaney K, Goodman ZD and Ishak KG: Hepatobiliary cystadenoma and cystadenocarcinoma. A light microscopic and immunohistochemical study of 70 patients. Am J Surg Pathol 18: 1078-1091, 1994.

15 Nakanuma Y, Uesaka K, Miyayama S, Yamaguchi H and Ohtsuka M: Intraductal neoplasms of the bile duct. A new challenge to biliary tract tumor pathology. Histol Histopathol 32: 1001-1015, 2017.

16 Nakanuma Y, Curabo MP, Franceschi S, Gores G, Paradis V, Sripa $\mathrm{B}$, Tsui WMS and Wee A: Intrahepatic cholangiocarcinoma. In: WHO Classification of Tumours of the Digestive System; World Health Organization of Tumours Fourth Edition. Bosman FT, Carneiro F, Hruban RH and Theise ND (eds.). Lyon: IARC: pp. 217-224, 2010.

17 Japanese Society of Hepato-Biliary-Pancreatic Surgery. In: General Rules for Clinical and Pathological Studies on Cancer of the Biliary Tract. The Sixth Edition (in Japanese). Miyazaki M (eds.). Tokyo: Kanehara Co., p. 45, 2013.

18 Gordon-Weeks AN and Jones K, Harriss E, Smith A and Silva $\mathrm{M}$ : Systematic review and meta-analysis of current experience in treating IPNB: clinical and pathological correlates. Ann Surg 263: 656-663, 2016.

19 Nanashima A, Sumida Y, Tomoshige K, Takeshita H, Shibata K, Sawai T, Yasutake T, Kinoshita N, Hayashi T, Nakanuma Y and Nagayasu T: A case of intraductal papillary neoplasm of the bile duct with stromal invasion. Case Rep Gastroenterol 2: 314-320, 2008.

20 Liver Cancer Study Group of Japan. In: The General Rules for the Clinical and Pathological Study of Primary Liver Cancer. The Sixth Edition (in Japanese). Kokudo N (ed.) Tokyo: Kanehara Co., p. 17, 2013.
21 Rocha FG, Lee H, Katabi N, DeMatteo RP, Fong Y, D'Angelica MI, Allen PJ, Klimstra DS and Jarnagin WR: Intraductal papillary neoplasm of the bile duct: A biliary equivalent to intraductal papillary mucinous neoplasm of the pancreas? Hepatology 56: 1352-1360, 2012.

22 Jung G, Park KM, Lee SS, Yu E, Hong SM and Kim J: Longterm clinical outcome of the surgically resected intraductal papillary neoplasm of the bile duct. J Hepatol 57: 787-793, 2012.

23 Fukumura Y, Nakanuma Y, Kakuda Y, Takase M and Yao T: Clinicopathological features of intraductal papillary neoplasms of the bile duct: a comparison with intraductal papillary mucinous neoplasm of the pancreas with reference to subtypes. Virchows Arch 471: 65-76, 2017.

24 Nanashima A, Sumida Y, Tamaru N, Nakanuma Y, Abo T, Tanaka K, Sawai T, Yasutake T, Nagayasu T, Hayashi T and Fukuda Y: Intraductal papillary neoplasm of the bile duct extending superficially from the intrahepatic to extrahepatic bile duct. J Gastroenterol 41: 495-499, 2006.

25 Nanashima A, Tobinaga S, Araki M, Kunizaki M, Abe K, Hayashi H, Harada K, Nakanuma Y, Nakagoe T, Takeshita H, Sawai $\mathrm{T}$ and Nagayasu T: Intraductal papillary growth of liver metastasis originating from colon carcinoma in the bile duct: report of a case. Surg Today 41: 276-280, 2011.

26 Tominaga T, Abo T, Kinoshita N, Murakami T, Sato Y, Nakanuma Y, Harada K, Masuda J, Nagayasu T and Nanashima A: A variant of multicystic biliary hamartoma presenting as an intrahepatic cystic neoplasm. Clin J Gastroenterol 8: 162-166, 2015.

27 Nanashima A, Sumida Y, Tobinaga S, Abo T, Takeshita H, Sawai T, Hidaka S, Fukuoka H and Nagayasu T: Characteristics of bile duct carcinoma with superficial extension in the epithelium. World J Surg 33: 1255-1258, 2009.

28 Fujikura K, Fukumoto T, Ajiki T, Otani K, Kanzawa M, Akita $\mathrm{M}$, Kido $\mathrm{M}$, $\mathrm{Ku} \mathrm{Y}$, Itoh $\mathrm{T}$ and Zen $\mathrm{Y}$ : Comparative clinicopathological study of biliary intraductal papillary neoplasms and papillary cholangiocarcinomas. Histopathology 69: 950-961, 2016.

29 Tsukahara T, Shimoyama Y, Ebata T, Yokoyama Y, Igami T, Sugawara G, Mizuno T, Yamaguchi J, Nakamura S and Nagino M: Cholangiocarcinoma with intraductal tubular growth pattern versus intraductal papillary growth pattern. Mod Pathol 29: 293$301,2016$.

30 Aishima S, Kubo Y, Tanaka Y and Oda Y: Histological features of precancerous and early cancerous lesions of biliary tract carcinoma. J Hepatobiliary Pancreat Sci 21: 448-452, 2014.

31 Nanashima A, Kinoshita N, Nakanuma Y, Zen Y, Sumida Y, Abo T, Hidaka S, Takeshita H, Yasutake T, Hayashi T and Nagayasu T: Clinicopathological features of "intraductal papillary neoplasm of the bile duct" and patient outcome after surgical resection. Hepatogastroenterology 55: 1167-1173, 2008.

32 Nanashima A, Kondo H, Nakashima M, Abo T, Arai J, Ishii M, Hidaka S, Kunizaki M, To K, Takeshita H, Yamasaki N, Tsuchiya $\mathrm{T}$ and Nagayasu T: Clinicopathological characteristics of multiple primary cancers in hepatobiliary and pancreas malignancies. Anticancer Res 35: 1073-1083, 2015.

33 Sakai Y, Tsuyuguchi T, Ishihara T, Sugiyama H, Miyakawa K, Yasui S, Eto R, Fujimoto T, Ohtsuka M, Miyazaki M and Yokosuka O: Usefulness of per-oral cholangioscopy in preoperative diagnosis of intraductal papillary neoplasm of the bile duct. Hepatogastroenterology 57: 691-693, 2010. 
34 Luvira V, Pugkhem A, Bhudhisawasdi V, Pairojkul C, Sathitkarnmanee E, Luvira V and Kamsa-Ard S: Long-term outcome of surgical resection for intraductal papillary neoplasm of the bile duct. J Gastroenterol Hepatol 32: 527-533, 2017.

35 Jang GW, Hwang S, Lee YJ, Kim KH, Park KM, Ahn CS, Moon DB, Ha TY, Song GW, Jung DH, Park GC and Lee SG: Clinicopathological features of the intraductal papillary neoplasms of the intrahepatic bile duct. Korean J Hepatobiliary Pancreat Surg 16: 138-141, 2012.

36 Okamoto A, Tsuruta K, Matsumoto G, Takahashi T, Kamisawa $\mathrm{T}$, Egawa $\mathrm{N}$ and Funata $\mathrm{N}$ : Papillary carcinoma of the extrahepatic bile duct: characteristic features and implications in surgical treatment. J Am Coll Surg 196: 394-401, 2003.

37 Zen Y: Controversies on intraductal papillary neoplasm of the bile duct (IPNB). JJBA 30: 212-219, 2016 (in Japanese with English abstract).

38 Bickenbach K, Galka E and Roggin KK: Molecular mechanisms of cholangiocarcinogenesis: Are biliary intraepithelial neoplasia and intraductal papillary neoplasms of the bile duct precursors to cholangiocarcinoma? Surg Oncol Clin N Am 18: 215-224, 2009.
39 Yamasaki S: Intrahepatic cholangiocarcinoma: macroscopic type and stage classification. J Hepatobiliary Pancreat Surg 10: 288-291, 2003.

40 Kim WJ, Hwang S, Lee YJ, Kim KH, Park KM, Ahn CS, Moon DB, Ha TY, Song GW, Jung DH, Park GC, Kim MH, Lee SK, Seo DW, Park do H, Lee SS and Lee SG: Clinicopathological features and long-term outcomes of intraductal papillary neoplasms of the intrahepatic bile duct. J Gastrointest Surg 20: 1368-1375, 2016.

Received January 9, 2018

Revised February 22, 2018

Accepted February 26, 2018 